\title{
Nanoscale
}

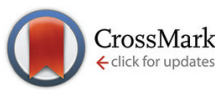

Cite this: Nanoscale, 2016, 8, 3579

Received 29th October 2015

Accepted 5th January 2016

DOI: $10.1039 / c 5 n r 07547 e$

www.rsc.org/nanoscale

\section{A novel lateral flow assay based on GoldMag nanoparticles and its clinical applications for genotyping of MTHFR C677T polymorphisms}

\author{
Wenli Hui, $\uparrow^{\mathrm{a}, \mathrm{b}}$ Sinong Zhang, $\dagger^{\mathrm{a}}$ Chao Zhang, ${ }^{\mathrm{a}}$ Yinsheng Wan, ${ }^{* \mathrm{c}}$ Juanli Zhu, ${ }^{\mathrm{b}}$ \\ Gang Zhao, ${ }^{\mathrm{d}}$ Songdi Wu, ${ }^{\mathrm{e}}$ Dujuan Xi, ${ }^{\mathrm{b}}$ Qinlu Zhang, ${ }^{\mathrm{b}}$ Ningning Li ${ }^{\mathrm{b}}$ and Yali Cui*a,b
}

Current techniques for single nucleotide polymorphism (SNP) detection require tedious experimental procedures and expensive and sophisticated instruments. In this study, a visual genotyping method has been successfully established via combining ARMS-PCR with gold magnetic nanoparticle (GoldMag)based lateral flow assay (LFA) and applied to the genotyping of methylenetetrahydrofolate reductase (MTHFR) C677T. C677T substitution of the gene MTHFR leads to an increased risk of diseases. The genotyping result is easily achievable by visual observation within 5 minutes after loading of the PCR products onto the LFA device. The system is able to accurately assess a broad detection range of initial starting genomic DNA amounts from 5 ng to 1200 ng per test sample. The limit of detection reaches 5 ng. Furthermore, our PCR-LFA system was applied to clinical trials for screening 1721 individuals for the C677T genotypes. The concordance rate of the genotyping results detected by PCR-LFA was up to $99.6 \%$ when compared with the sequencing results. Collectively, our PCR-LFA has been proven to be rapid, accurate, sensitive, and inexpensive. This new method is highly applicable for C677T SNP screening in laboratories and clinical practices. More promisingly, it could also be extended to the detection of SNPs of other genes.

\section{Introduction}

In recent years, detection of single nucleotide polymorphisms (SNPs) has attracted a great deal of attention because of its various applications in the diagnosis and treatment of genetic diseases and use of medicines. ${ }^{1,2}$ With the development of the next-generation sequencing (NGS) technology, it is widely used in the sequencing of human genomes to look for disease susceptibility genes. ${ }^{3}$ With its accuracy, sequencing is always regarded as a golden standard for nucleic acid analysis, but as per the scale of investigation and the subsequent massive data analysis, sequencing is more suitable for discovery of novel SNPs $^{4-6}$ than direct detection of specifically known SNPs. Other technologies including DNA microarrays, ${ }^{7-9}$ real-time polymerase chain reaction (RT-PCR), ${ }^{10,11}$ high resolution melting (HRM), ${ }^{12}$ MassARRAY, ${ }^{13,14}$ the multiplex PCR-RFLP

\footnotetext{
${ }^{a}$ College of Life Sciences, Northwest University, Xi'an, 710069, China. E-mail: yalicui@nwu.edu.cn

${ }^{b}$ National Engineering Research Center for Miniaturized Detection Systems, Northwest University, Xi'an, 710069, China

${ }^{c}$ Department of Biology, Providence College, Providence, RI 02918, USA. E-mail: yswan@providence.edu

${ }^{d}$ Xijing Hospital, the Fourth Military Medical University, Xi'an, 710032, China

${ }^{e}$ No. 1 Hospital of Xi'an City, Xi'an, 710068, China

$\dagger$ These authors contributed equally to this study and share first authorship.
}

method $^{15}$ and isothermal DNA amplification ${ }^{16,17}$ also offer sensitive tools to detect SNPs. However, these techniques require tedious experimental procedures and expensive and sophisticated instruments that may not be available in many laboratories. Therefore, an easy-to-operate and affordable onsite technique for genotyping with high efficiency has become indispensable and urgently needed.

There is a growing interest in the development of nanoparticle-based DNA detection methods, some of which have been successfully applied in clinical settings. ${ }^{18-22}$ Nanoparticle-associated lateral flow assay (LFA) for nucleic acid analysis, as a simple and rapid method, enables visual detection of the target DNA, and perhaps more importantly, skips complicated steps including pipetting, incubation, washing, and data analysis. ${ }^{23,24}$ Mao et al. reported a nucleic acid biosensor based on the oligonucleotide functionalized Au-NPs and LFA device. ${ }^{25}$ Kalogianni et al. presented lateral flow tests exploiting carbon nanoparticles as reporters. ${ }^{26}$ In these reports, LFA test strips rely on the hybridization reaction and are more suitable for detection of the target DNA sequence rather than SNPs.

Gold magnetic nanoparticles are novel composite particles that integrate the superparamagnetism of $\mathrm{Fe}_{3} \mathrm{O}_{4}$ nanoparticles and the surface chemistry of the Au component. The different structures with core/shell, dumbbell-like and flower-shape of these nanoparticles have been reported..$^{27-29}$ Herein, the 
$\mathrm{Fe}_{3} \mathrm{O}_{4} / \mathrm{Au} / \mathrm{Fe}_{3} \mathrm{O}_{4}$ configuration (nanoflowers) with $38 \mathrm{~nm}$ diameter was synthesized ${ }^{30}$ and used as a carrier to set up a device for SNP detection. Compared to other matrix nanoparticles, our patented PAA (poly-acrylic acid) modification of GoldMag nanoparticles ensures the significantly elevated stableness and compatibility of the particles for biological interactions. Our nanoparticle based lateral-flow immunoassay was also previously reported to rapidly, specifically, and accurately analyze the TP antibody at the laboratory and clinical level. $^{31}$

Using MTHFR C677T genotyping as a model, we have developed a sensitive, specific, rapid, and cost-effective method for SNP detection via integrating the amplification refractory mutation system (ARMS)-PCR with GoldMag-based lateral flow assay (LFA). C677T is the most common SNP on methylenetetrahydrofolate reductase, which is a key enzyme in folate metabolism. ${ }^{32} \mathrm{C}>\mathrm{T}$ substitution results in a reduced activity of this thermo-labile enzyme ${ }^{33}$ and causes not only folate metabolic disorders but also accumulation of homocysteine (Hcy). It has been reported that $\mathrm{C677T}$ polymorphism is associated with a high risk of diseases ${ }^{34-39}$ such as cancer, neurological disorders, cardiovascular diseases, and pregnancy complications. Detection of MTHFR C677T may help predict risk for diseases and guide the folate supplement to prevent diseases $^{40-42}$ such as stroke, neural tube defects and Down's syndrome.

\section{Materials and methods}

\section{Materials and reagents}

PAA (poly-acrylic acid) modified gold magnetic nanoparticles (PGMNs) and lateral flow strips were from Xi'an GoldMag Nanobiotech Co., Ltd (Xi'an, Shaanxi, PRC). Water (18.2 $\mathrm{M} \Omega \mathrm{cm}$ ) used for all work in this report was purified by using a Barnstead Nanopure Water system. All chemicals were of analytical grade and purchased from reputable vendors. Buffer was prepared according to standard laboratory procedures. Anti-digoxin antibody was purchased from Meridian Life Science, Inc. (Saco, ME, USA). Streptavidin was obtained from Promega Biotech Inc. (Madison, WI, USA). Goat anti-mouse IgG was from Joey Bioscience Inc. (Shanghai, PRC). HotMaster Taq DNA polymerase and $10 \times$ buffer and $1 \times$ TE both were purchased from TIANGEN (Beijing, PRC). dNTPs and uracil-DNA glycosylase (UDG) were obtained from Shinegene (Shanghai, PRC). $\mathrm{MgCl}_{2}$ (25 mM) was purchased from Thermo Scientific (Shanghai, PRC). All oligonucleotides used in this work were synthesized by Invitrogen (Shanghai, PRC). The commercial genotyping kits (PCR-microarray) were from Baio technology (Shanghai, PRC).

\section{DNA extraction}

DNA was extracted from $200 \mu \mathrm{L}$ of blood samples using a whole blood genomic DNA isolation kit from Xi'an GoldMag Nanobiotech Co., Ltd (Xi'an, Shaanxi, PRC) according to the manufacturer's instructions. Briefly, $40 \mu \mathrm{L}$ proteinase $\mathrm{K}$,
$200 \mu \mathrm{L}$ of whole blood and $400 \mu \mathrm{L}$ of lysis buffer were added into a microfuge tube. The samples were then mixed well by pipetting and incubated at $56{ }^{\circ} \mathrm{C}$ for $20 \mathrm{~min}$. Then $100 \mu \mathrm{L}$ of GoldMag $^{\circledR}$ particles and $400 \mu \mathrm{L}$ of binding buffer were added to the tube which was incubated at room temperature for $5 \mathrm{~min}$. The tube was then placed on the magnetic separator for 2 min to magnetically separate and discard the supernatant. The GoldMag ${ }^{\circledR}$-DNA complexes were washed with $600 \mu \mathrm{L}$ of washing buffer-1 and $800 \mu \mathrm{L}$ of wash buffer-2. $200 \mu \mathrm{L}$ of elution buffer was added to the tube and the mixture was incubated at $56{ }^{\circ} \mathrm{C}$ in a water bath for $5 \mathrm{~min}$. The tube was put back on the magnetic separator for $3 \mathrm{~min}$ until the supernatant was clear. The supernatant (DNA solution) was transferred to another tube and ready to use.

\section{PCR amplification}

According to the principle of ARMS-PCR, ${ }^{43,44}$ the reverse primer was designed as the common primer, and the forward primers are allele specific primers since the nucleotide at their 3 ' terminus corresponds to the SNP site. To detect the genotype of each sample, two complementary reactions ( $\mathrm{M}$ tube and WT tube) were run separately using the same DNA template. Each PCR reaction volume was $50 \mu \mathrm{L}$ containing $10 \times$ PCR buffer (10 mM Tris HCl, $50 \mathrm{mM} \mathrm{KCl}$ ), $0.2 \mathrm{mM}$ of each dNTP (dATP, dCTP, dGTP, dUTP), $3 \mathrm{mM}$ of $\mathrm{MgCl}_{2}, 0.5 \mathrm{U}$ of Hotmaster Taq DNA polymerase, 0.5 U of UDG polymerase, 50 $\mathrm{nM}$ reverse primer, and $3 \mu \mathrm{L}$ genomic DNA with the concentrations of $10-400 \mathrm{ng} \mu \mathrm{L}^{-1} .50 \mathrm{nM}$ of the forward (M) primer in the $\mathrm{M}$ tube and the forward (WT) primer in the WT tube were used separately. The primer sequences: forward (M) primer 5'-AGAAGGTGTCTGCGGGATT-3'; forward (WT) primer 5'-GAGAAGGTGTCTGCGGGATC-3'; reverse primer 5'-GAAAGATCCCGGGGACGATG-3'. The ABI PCR thermal cycler Dice was used for the amplification. PCR was commenced with two initial denaturation steps at $50{ }^{\circ} \mathrm{C}$ for $2 \mathrm{~min}$ and $95{ }^{\circ} \mathrm{C}$ for $5 \mathrm{~min}$, followed by 26 cycles of denaturation at $94{ }^{\circ} \mathrm{C}$ for $30 \mathrm{~s}$, annealing at $60{ }^{\circ} \mathrm{C}$ for $30 \mathrm{~s}$, and extension at $65{ }^{\circ} \mathrm{C}$ for $1 \mathrm{~min}$. The final extension step was at $65^{\circ} \mathrm{C}$ for $10 \mathrm{~min}$.

\section{Conjugation of PGMNs with anti-digoxin antibody}

$1 \mathrm{mg}$ of PAA-GMNs was equilibrated in $600 \mu \mathrm{L}$ of phosphate buffer $(1 \times \mathrm{PB}, \mathrm{pH} 7.2)$ and activated by EDC, anti-digoxin antibody was then added to the particles. This mixture was shaken at $180 \mathrm{rpm}$ for $1 \mathrm{~h}$ at $22^{\circ} \mathrm{C}$. After $1 \mathrm{~h}$ of incubation, the antidigoxin antibody functionalized PAA-GMN conjugates were magnetically separated and then suspended in a PB suspension buffer $(1 \times \mathrm{PB}, \mathrm{pH} 7.2$, containing $1 \% \mathrm{BSA})$ at $2-8{ }^{\circ} \mathrm{C}$ until use.

\section{LFA device}

Via a BioJet dispenser (HM3010, BioDot Inc.), streptavidin and goat anti-mouse IgG were pre-immobilized respectively in a defined test line ( $\mathrm{T}$-line) and a control line (C-line) on a porous nitrocellulose membrane. Then, the probe solution containing PGMNs with an anti-digoxin antibody was dispensed on the conjugate pad of LFA strips. These strips were placed in a card box and stored in a sealed aluminum foil bag with desiccant 
silica gel at room temperature. The strips remain stable for 12 months.

\section{Evaluation of C677T genotypes via LFA}

After PCR amplification, the whole reaction volume $(50 \mu \mathrm{L})$ in two tubes were loaded on the sample pads of the LFA strips respectively and the results were analysed. The reference DNA samples with CC, CT and TT genotypes confirmed by sequencing were used to validate the method. In order to ensure the specificity of the assay, an additional mismatch at the penultimate nucleotide of the $3^{\prime}$ terminus was introduced ${ }^{45}$ in the process of primer design. The sensitivity was evaluated by varying the concentration of DNA samples.

\section{Clinical application and statistical analysis}

1721 human whole blood samples were obtained from six hospitals including 504 cases from Xiangya Hospital CentralSouth University (Changsha, PRC), 313 cases from Shaanxi Provincial People's Hospital (Xi'an, PRC), 200 cases from Hunan Provincial People's Hospital (Changsha, PRC), 175 cases from Peking Union Medical College Hospital (Beijing, PRC), 341 cases from Beijing Tiantan Hospital (Beijing, PRC) and 188 cases from NanFang Hospital, Southern Medical University (Guangzhou, PRC). Appropriate ethical and governance permission was obtained from the local authorities prior to blood sample collection.

The genomic DNA samples extracted from whole blood were tested in a double-blind trial. The genotype of each sample was analysed by PCR-GoldMag based-LFA and compared with the results detected by the commercial genotyping kit (PCR-DNA microarray) or DNA sequencing. Samples displaying inconsistent results with the commercial kit were retested via BGI's sequencing as the third party test. Based on the statistics data, the coincidence rate of three genotypes and total agreements were calculated to evaluate the accuracy of our method.

\section{Results and discussion}

\section{Principles of PCR-lateral flow assay}

To detect polymorphism of MTHFR C677T, we established the PCR-LFA method, which technically combines ARMS-PCR with LFA.

The principle of PCR-LFA is schematically illustrated in Fig. 1. With two sets of allele-specific primers (corresponding to the wild type sequence and mutation sequence), the ARMS-PCR technique is used to amplify target fragments in two tubes (Fig. 1A). For one particular sample, an equal amount of genomic DNA was added to the above two separate PCR tubes, one as the $\mathrm{M}$ tube with the forward (M) primer to detect the "T" allele and the other as the WT tube with the forward (WT) primer to detect the "C" allele. Forward ( $\mathrm{M}$ and WT) and reverse (common) primers are $5^{\prime}$ end-labelled with digoxin and biotin, respectively. The PCR target fragments are synthesized while the 3 -end of the primer is complementary with the template (Fig. 1B).

A LFA device is composed of five parts: a sample pad, a conjugate pad, a strip of nitrocellulose membrane, an absorbent pad, and a plastic cushion. After PCR amplification, PCR products of two tubes are loaded onto the sample pads of two LFA strips separately. PCR target fragments, if any, are complexed with the pre-fabricated PGMN-anti-digoxin antibody conjugates on the adjacent conjugate pad. The subsequent DNAPGMN-anti-digoxin antibody conjugates migrate across the membrane until being captured by pre-immobilized streptavidin on the test line ( $\mathrm{T}$ line) with a result of a red band. The colour development on the $\mathrm{T}$ line can thus suggest whether there are target fragments in the PCR reactions. The excessive amount of PGMN-anti-digoxin antibody conjugates is captured by using goat anti-mouse IgG on the control line (C line), indicating the efficacy of the system (Fig. 1C).

A final genotyping result of a sample is a combinational visual presentation as per the colour development on the $\mathrm{T}$ lines of both strips (Fig. 1D). For the homozygous sample (677 $\mathrm{TT}$ ), a distinct red band is observable on the T line of the strip used only for the M tube but not for the WT tube. In contrast, for the wild-type sample (677 CC), the red band shows exclusively on the strip receiving the WT tube but not the M tube. However, when red bands with similar intensities are present on the $\mathrm{T}$ lines of both strips, it indicates a heterozygous sample (677 CT).

The result by agarose gel electrophoresis for MTHFR C677T genotyping shows that the fragment length for the amplicon is 141 bp (Fig. 1E). 26 cycles of PCR amplification suffice our LFA detection. However, electrophoresis requires at least 32 cycles followed by a series of time-consuming steps. In addition, the C677T genotyping results detected by sequencing are displayed as a comparison (Fig. 1F).

PCR-LFA combines simple, cost-effective ARMS-PCR with quick LFA. Our PCR-LFA is faster than existing methods. After ARMS-PCR, the lateral flow device is used to detect PCR products. It takes only $5 \mathrm{~min}$ to obtain the detection results without the need for expensive or high-end instruments. The whole process for the genotyping of MTHFR C677T could be analysed within two hours. Our assay skipped or minimized various experimental steps, such as pipetting, gel casting/ purchasing, DNA separation, and UV visualization. We also proved that our method is more convenient than hybrid based microarray methods or other reported nucleic acid lateral flow assays. ${ }^{46,47}$ Therefore, this method can be used in the laboratories of all levels of hospitals and medical institutions, especially for laboratories with limited resources.

\section{Optimization of ARMS-PCR and LFA system for MTHFR genotyping}

To improve the sensitivity and specificity of our method for MTHFR C677T genotyping, we systematically optimized the ARMS-PCR procedure, LFA strip preparation and detecting conditions. 

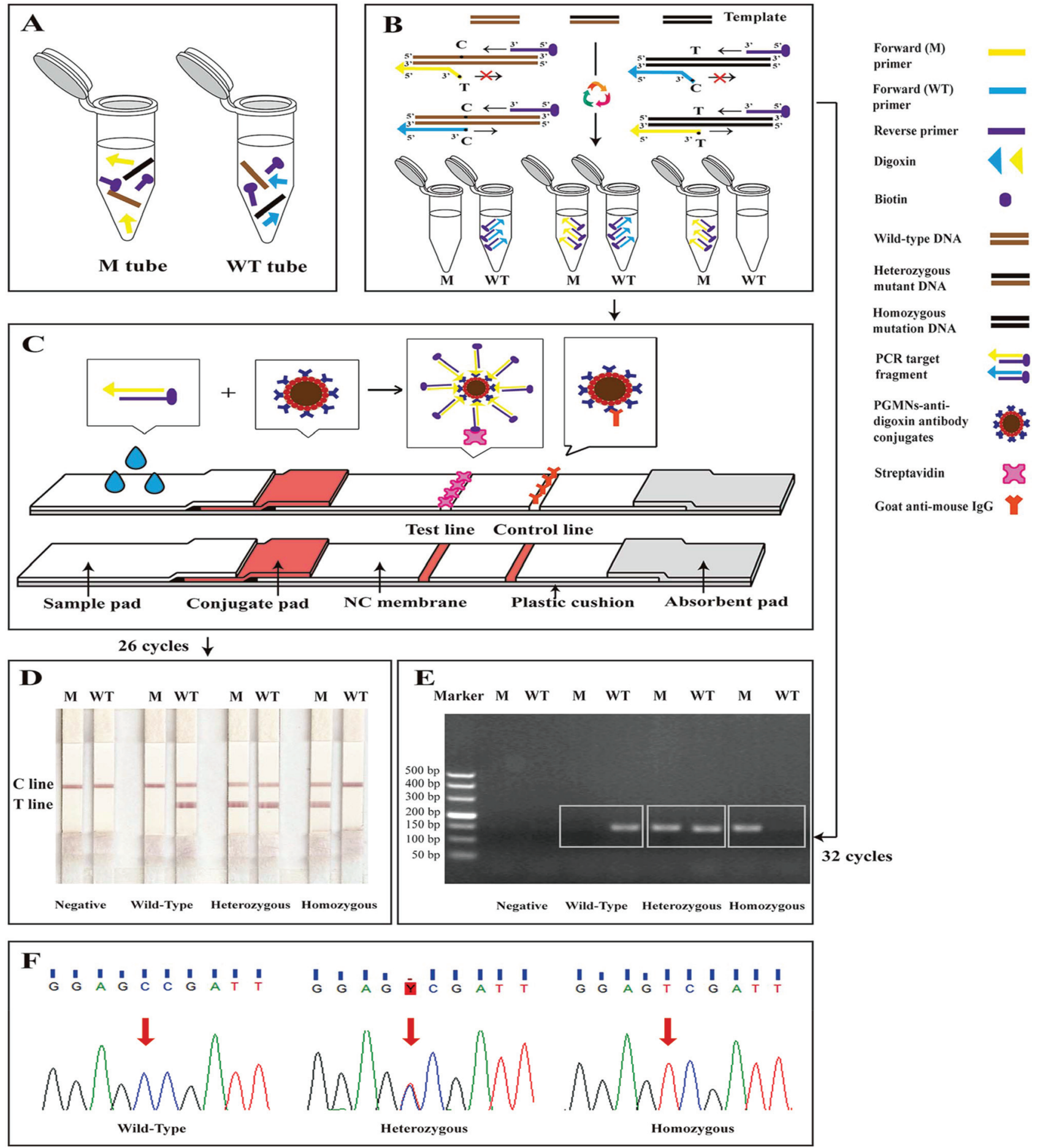

Fig. 1 Schematic diagram of the PCR-lateral flow assay (LFA) system. (A) Detecting one sample requires two tubes: M and WT tubes. (B) The process of ARMS-PCR. The PCR target fragment is synthesized while the 3 '-end of the primer is complementary with the template. (C) After PCR amplification, PCR products are loaded on the sample pad of LFA strips. The target fragments carrying the labels of biotin and digoxin are able to conjugate with the PGMN-anti-digoxin antibody complex and thus forms a further complex which is captured by streptavidin on the test line with an appearance of a red band. The excessive PGMN-anti-digoxin antibody complex can be precipitated by the goat anti-mouse IgG on the control line. (D) The genotyping result of homozygous, heterozygous and wild type sample by PCR-LFA. M = M tube. WT = WT tube. (E) The agarose gel electrophoresis results showing the detection of MTHFR C677T by ARMS-PCR. M = M tube. WT = WT tube. (F) The sequencing results for MTHFR C677T genotyping. 

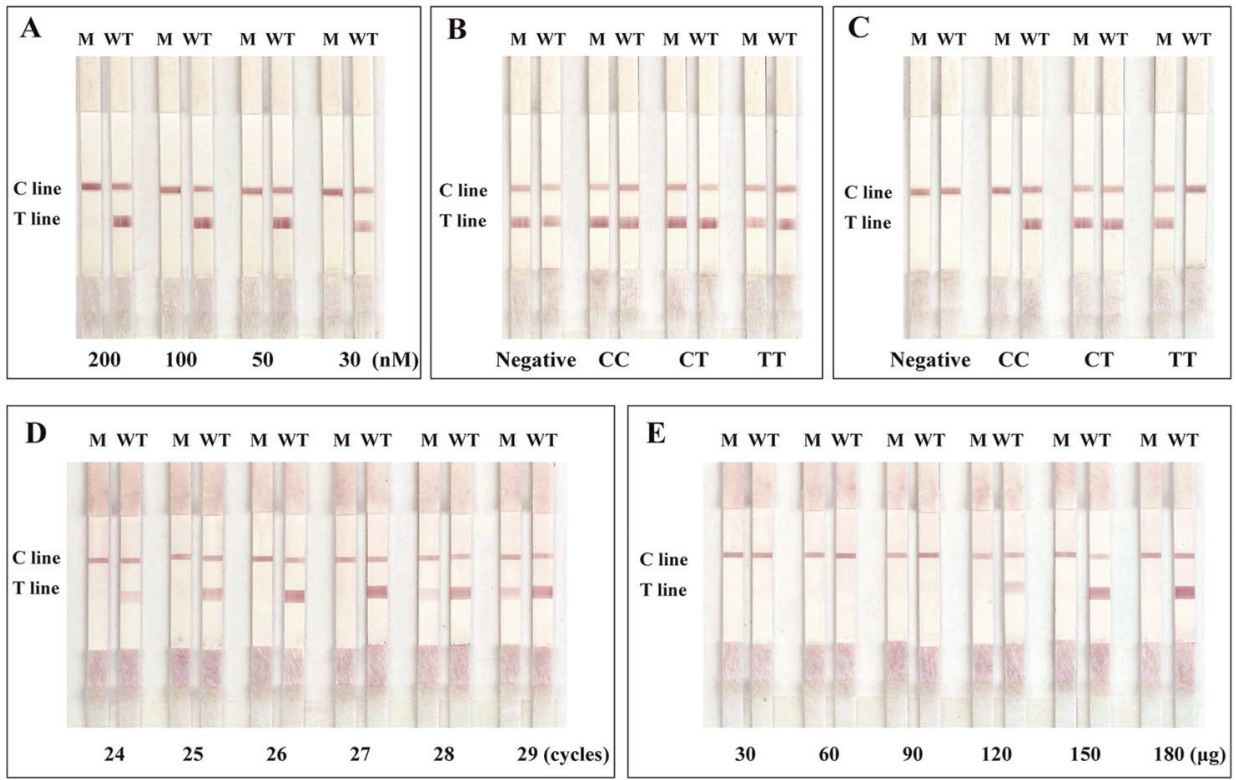

Fig. 2 Optimization of the detection system. $M=M$ tube. WT $=W T$ tube. (A) The concentration of primers. $50 \mathrm{nM}$ primer was proved to be optimal. (B) Addition of the PCR template comprising the genuine genomic DNA and the carryover PCR products from previous PCR reaction into the ARMS-PCR mix. Without UDG, the results were affected by PCR products. (C) The effect of UDG that was used to prevent contamination. The results were not affected from the carryover PCR products. (D) The cycles of PCR amplification. 26 cycles were the optimal. (E) The test of the amount of anti-digoxin antibody conjugated with PGMNs with $150 \mu \mathrm{g}$ of anti-digoxin as the optimum.

ARMS-PCR. To obtain the optimal performance, we carefully considered the design of primers and the concentration of primers, the use of dUTP and uracil-DNA glycosylase, and the PCR cycles. In order to ensure the specificity, an additional mismatch at the penultimate nucleotide of the $3^{\prime}$ terminus of allele specific forward primers was introduced based on the principle of ARMS-PCR. ${ }^{45}$ To determine the optimal concentration of the primers, different concentrations $(200,100,50$, $25 \mathrm{nM}$ ) of each primer were used into the ARMS-PCR mix. The results showed that $50 \mathrm{nM}$ primers were optimal for MTHFR C677T genotyping (Fig. 2A). Uracil-DNA glycosylase (UDG) is an enzyme utilized in our method to eliminate carryover PCR products containing dUTP. A simple digestion step $\left(50{ }^{\circ} \mathrm{C}\right.$, 2 min) was used prior to the subsequent PCR reaction. PCR products from previous PCR operation (i.e. the possible contaminant) and the genomic DNA need to be tested were together added into the tubes as the template. Without UDG, the PCR products displayed false positive results, as shown in Fig. 2B, all genotyping results were heterozygous including the negative control. The use of UDG ensures amplification of the desired genomic DNA (Fig. 2C). Therefore, in a new reaction, residual amplicons from previous PCR will be digested, only the desired DNA templates will be amplified and remain unaffected. We also tested PCR cycles (e.g. 25, 26, 27, 28, 29 cycles), considering that may affect the sensitivity and specificity of the method. The data showed that the optimal cycle number was 26 in our system (Fig. 2D).

Lateral flow assay device. We optimized the amount of antidigoxin antibody conjugated with PGMNs. $1 \mathrm{mg}$ of PAA- modified GoldMag nanoparticles was conjugated with various concentrations of digoxin antibody (Fig. 2E). Based on the data, $150 \mu \mathrm{g}$ of digoxin antibodies per mg of PGMNs as the optimum offered a cost-effective readout signal. Other parameters, including the $\mathrm{pH}$ of the buffer, the type of nitrocellulose membrane, and the lateral flow time, were also investigated and optimized (data not shown).

Validation of PCR-LFA. Under optimal experimental conditions, we further examined the performance of the PCR-LFA with different concentrations of genomic DNA. We also evaluated the sensitivity and specificity of PCR-LFA. A gradient of template assessment was prepared (e.g. 1, 5, 10, 30, 50, 100, $300,500,800,1000,1200 \mathrm{ng}$ of genomic DNA) for PCR reactions of 26 cycles. The concomitant PCR amplicons were detected by using the LFA strips (Fig. 3). When the dosage of the initial template was in the range of 5-1200 ng, the PCR amplification efficiency significantly improved as the dose of the template increased. Even when the dose was up to 1200 $\mathrm{ng}$, the specificity of the test remained high with no false-positive result. Normally, the concentration of genomic DNA extracted from human blood samples is in the range of 10-400 ng $\mu \mathrm{L}^{-1}$. Therefore, in this method, the DNA dilution process can be omitted.

Under our optimized conditions and signal amplifications, the detection limit of PCR-LFA can reach $5 \mathrm{ng}$ of the starting DNA sample, which is comparable to the commercial kit (PCR-DNA microassay). Our optimized method also exhibits high specificity with no false positive result. Higher sensitivity but no false positive readout makes this method unique and 
$677 \mathrm{CC}$
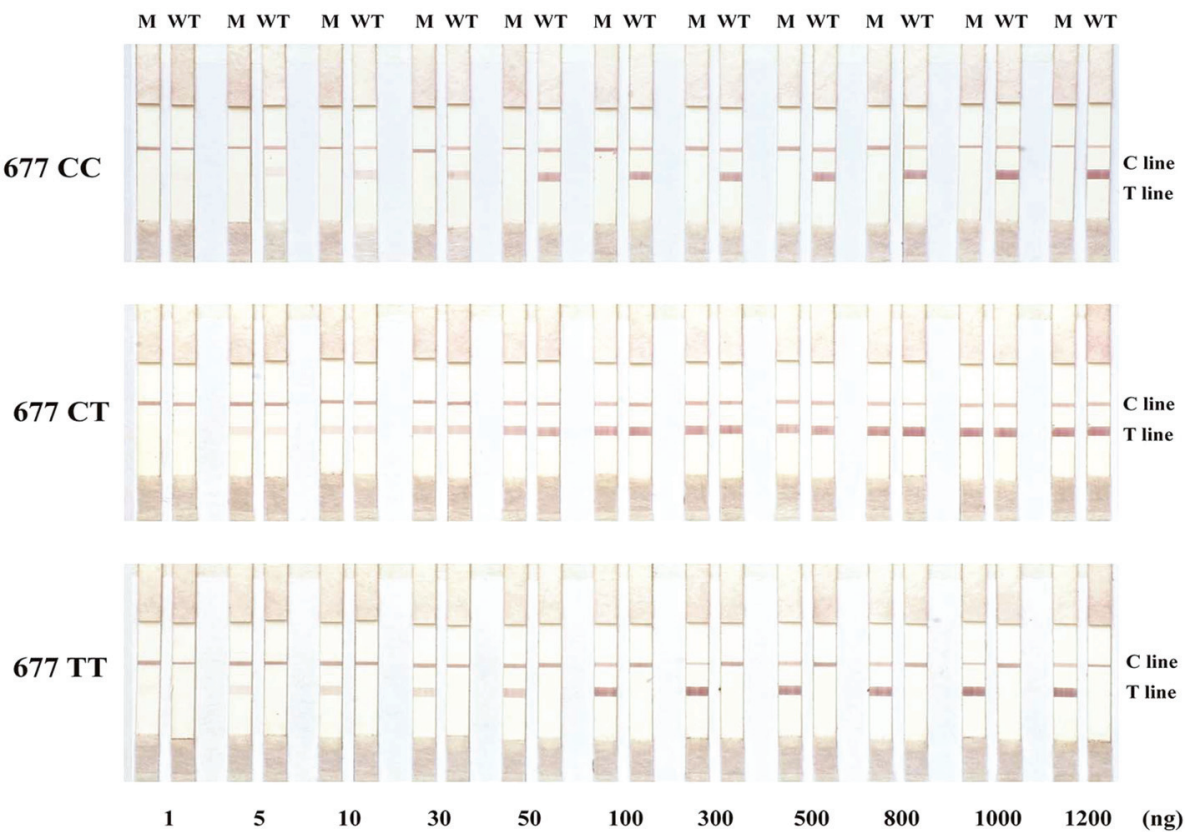

Fig. 3 LFA strips after analysis of homozygous DNA (TT), heterozygous DNA (CT), wild-type DNA (CC) based on ARMS-PCR. M = M tube. WT = WT tube. Using template dosage gradient to verify the sensitivity and specificity, in the dose range of 5-1200 ng, the detection limit can reach 5 ng. The method exhibits high specificity with no false positive result.

more applicable. Furthermore, in the PCR part of our assay, we methodologically introduced mismatches at the 3rd nucleotide from the 3 -ends of the primers, and found that this modification has a crucial impact on the specificity of our method, as some allele-specific primers completely lost specificity upon removal of the mismatch. ${ }^{48}$ This would favour clinical applications that demand unconditional specificity and accuracy, in addition to the speed of the assay. Technically, the capacity of antibody conjugation upon nanoparticles is critical for the assay. In general, the conjugating capacity of other kinds of nanoparticles with antibodies is difficult to reach $50 \mu \mathrm{g} \mathrm{mg}{ }^{-1}$. However, due to the novel GoldMag nanoparticle structure (nanoflowers), ${ }^{30}$ in our method, the conjugated antibodies can achieve more than $100 \mu \mathrm{g} \mathrm{mg}^{-1}$. This ensures the sensitivity and stability of our established PCR-lateral flow assay. ${ }^{30,31}$

\section{Clinical applications}

To further validate and extend our PCR-LFA method for the SNP of MTHFR, we carried out a double-blind trial with 1721 clinical samples. Each sample was tested by using our PCR-LFA strips and the commercial genotyping kit (PCR-DNA microarray) or DNA sequencing as a comparison.

1192 samples from Xiangya Hospital Central-South University, Shaanxi Provincial People's Hospital, Hunan Province People's Hospital and Peking Union Medical College Hospital were tested by using the commercial genotyping kit (PCR-DNA microarray). The other 529 samples from Beijing Tiantan Hospital and NanFang Hospital, Southern Medical University were tested by DNA sequencing. The genotype-specific concordance among the three methods is shown in Table 1.
For the 1192 samples, the statistical data showed that there were 33 discrepant samples and they were addressed via BGI's sequencing as a third party. DNA sequencing analysis revealed that the results of 26 samples were identical to the PCR-LFA method, 7 samples were agreeable with the commercial kit (PCR-DNA microarray). The data indicate that compared to the commercial kit, PCR-LFA is able to well serve as a more accurate assessing tool. The final consistency rates for CC, CT, TT types were $99 \%, 100 \%$, and $98.78 \%$, respectively. For the 529 samples, the results of PCR-LFA were in good agreement with the sequencing results, and the consistency rate was $100 \%$. These results clearly demonstrate that our new method is comparable to the DNA sequencing in MTHFR C677T genotyping.

Testing for MTHFR 677 genotypes of 1721 clinical samples reveals that PCR-LFA outperforms the commercially available kit at the level of accuracy, and is also able to match the sequencing method, by obtaining the concordance rate of genotyping up to $99.6 \%$. For the remaining 7 discrepant samples, we used PCR-LFA to re-test. The results were in accordance with the sequencing data (re-test results were not counted in clinical trials). Compared with the commercial kit and sequencing results, the consistency rates for CC, CT and TT types were $99.2 \%, 100 \%$, and $99.2 \%$, respectively. The total consistency rate was $99.6 \%$.

In addition, we analysed the genotype and allele frequency of 1721 cases (Fig. 4). The genotype frequencies of MTHFR 677 CC, CT, TT types were $28.82 \%$ (492 cases), $49.22 \%$ ( 851 cases) and $21.96 \%$ (378 cases) (Fig. 4A). The allele frequency for the C allele was $53.43 \%$ and the $\mathrm{T}$ allele was $46.57 \%$ (Fig. $4 \mathrm{~B}$ ). The 
Table 1 Type-specific concordance between PCR-lateral flow assay and PCR-DNA microarray or direct sequencing

\begin{tabular}{|c|c|c|c|c|c|c|c|c|c|c|c|c|}
\hline & \multirow[b]{2}{*}{$\begin{array}{l}\text { Sample } \\
\text { Size }\end{array}$} & \multirow[b]{2}{*}{ Genotype } & \multicolumn{4}{|c|}{$\begin{array}{l}\text { Commercial genotype kit } \\
\text { (PCR-DNA microarray) }\end{array}$} & \multicolumn{4}{|c|}{ Sequencing } & \multirow[b]{2}{*}{ Total } & \multirow[b]{2}{*}{ Agreement\% } \\
\hline & & & $\mathrm{CC}$ & CT & TT & $\begin{array}{l}\text { Discrepant } \\
\text { samples }\end{array}$ & $\mathrm{CC}$ & CT & $\mathrm{TT}$ & $\begin{array}{l}\text { Discrepant } \\
\text { samples }\end{array}$ & & \\
\hline \multirow[t]{3}{*}{ Hospital $^{a, b, c, d}$ (PCR-LFA) } & \multirow[t]{3}{*}{1192} & $\mathrm{CC}$ & 387 & 8 & 3 & 11 & 11 & 0 & 0 & 0 & 398 & $99 \%$ \\
\hline & & $\mathrm{CT}$ & 14 & 556 & 5 & 19 & 4 & 12 & 3 & 7 & 575 & $100 \%$ \\
\hline & & TT & 1 & 2 & 216 & 3 & 0 & 0 & 3 & 0 & 219 & $98.78 \%$ \\
\hline & 529 & TT & - & - & - & - & 0 & 0 & 156 & 0 & 156 & $100 \%$ \\
\hline \multirow{3}{*}{ Total (PCR-LFA) } & \multirow[t]{3}{*}{1721} & $\mathrm{CC}$ & 398 & 0 & 0 & 0 & 94 & 0 & 0 & 0 & 492 & $99.2 \%$ \\
\hline & & $\mathrm{CT}$ & 4 & 568 & 3 & 7 & 0 & 279 & 0 & 0 & 854 & $100 \%$ \\
\hline & & TT & 0 & 0 & 219 & 0 & 0 & 0 & 156 & 0 & 375 & $99.2 \%$ \\
\hline
\end{tabular}

${ }^{a}$ Xiangya Hospital Central-South University. ${ }^{b}$ Hunan Provincial People's Hospital. ${ }^{c}$ Shaanxi Provincial People's Hospital. ${ }^{d}$ Peking Union Medical College Hospital. ${ }^{e}$ Beijing Tiantan Hospital. ${ }^{f}$ NanFang Hospital, Southern Medical University.
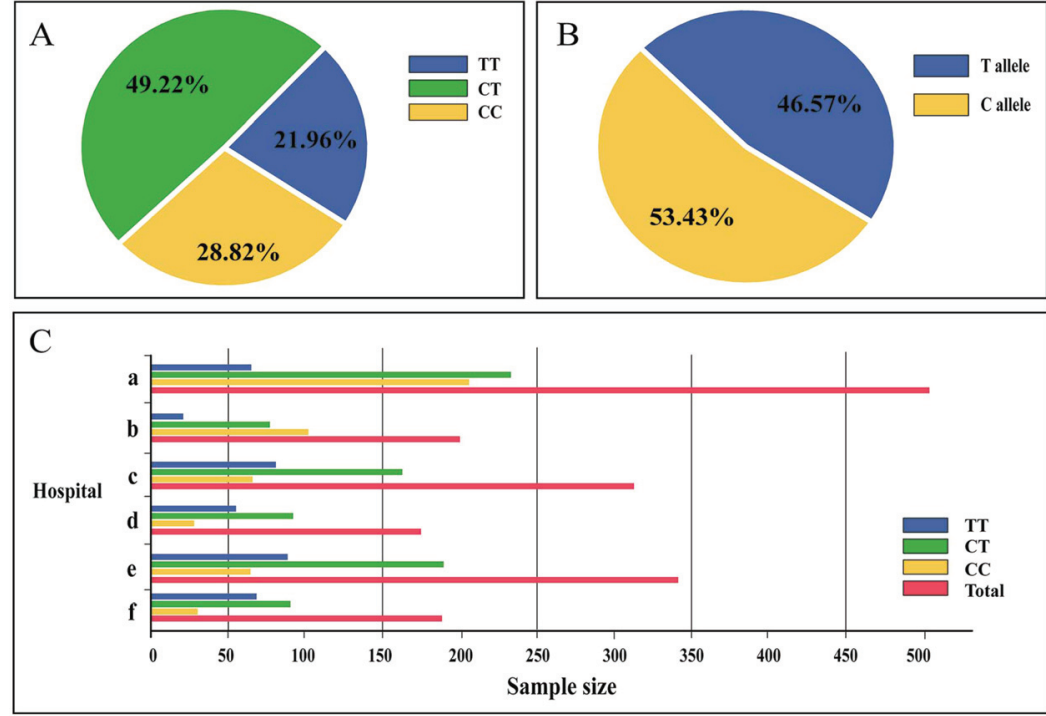

Fig. 4 Pie chart for the genotype and allele frequency of MTHFR C677T with 1721 cases. (A) Genotype frequencies of MTHFR C677T. (B) Allele frequencies of $T$ and $C$ alleles. (C) The sample size data for genotyping of six hospitals. (a) Xiangya Hospital Central-South University. (b) Hunan Provincial People's Hospital. (c) Shaanxi Provincial People's Hospital. (d) Peking Union Medical College Hospital. (e) Beijing Tiantan Hospital. (f) NanFang Hospital, Southern Medical University.

sample size data for genotyping of six hospitals are shown in Fig. 4C.

\section{Conclusions}

In this report, we presented a PCR-lateral flow assay for detection of SNP from genomic DNA samples, using our patented gold magnetic nanoparticles (GoldMag) as a carrier. This is the first report that a system combined the amplification refractory mutation system (ARMS)-PCR with GoldMag-based lateral flow assay (LFA) for genotyping. Our data have demonstrated that this assay is highly applicable for detection of SNP of MTHFR C677T in clinical practice due to its unparalleled advantages, such as superior sensitivity and specificity, low cost, easy operation, simple procedure, and no need for expensive instruments. Since detection for this SNP has significant clinical values, in our laboratory this method has already been extended to SNP detection of other genes related to folic acid metabolism. It is envisaged that our newly established PCR-LFA could be quickly adapted for the detection of other SNPs of genes that are associated with disease risk, drug metabolism, or drug reaction.

\section{Acknowledgements}

This study was supported by the Project of National Great New Drug Research and Development China (No. 2012ZX09506001- 
001, YC), the National Natural Science Foundation of China (no. 31200749) and a grant from the National Institute of Health (no. P20RR016457 from the INBRE Program of the National Center for Research Resources, YW).

\section{Notes and references}

1 A. R. Everitt, S. Clare, T. Pertel, S. P. John, R. S. Wash, S. E. Smith, C. R. Chin, E. M. Feeley, J. S. Sims, D. J. Adams, H. M. Wise, L. Kane, D. Goulding, P. Digard, V. Anttila, J. K. Baillie, T. S. Walsh, D. A. Hume, A. Palotie, Y. Xue, V. Colonna, C. Tyler-Smith, J. Dunning, S. B. Gordon, I. I. Gen, M. Investigators, R. L. Smyth, P. J. Openshaw, G. Dougan, A. L. Brass and P. Kellam, Nature, 2012, 484, 519-523.

2 J. Moore, A. J. McKnight, M. J. Simmonds, A. E. Courtney, R. Hanvesakul, O. J. Brand, D. Briggs, S. Ball, P. Cockwell, C. C. Patterson, A. P. Maxwell, S. C. Gough and R. Borrows, JAMA, 2010, 303, 1282-1287.

3 M. L. Metzker, Nat. Rev. Genet., 2010, 11, 31-46.

4 P. S. Hendre, R. Kamalakannan and M. Varghese, Plant Biotechnol. J., 2012, 10, 646-656.

5 J. R. Grant, A. S. Arantes, X. Liao and P. Stothard, Bioinformatics, 2011, 27, 2300-2301.

6 M. Ahsan, X. Li, A. E. Lundberg, M. Kierczak, P. B. Siegel, O. Carlborg and S. Marklund, Front. Genet., 2013, 4, 226.

7 J. Li, Y. Huang, D. Wang, B. Song, Z. Li, S. Song, L. Wang, B. Jiang, X. Zhao, J. Yan, R. Liu, D. He and C. Fan, Chem. Commun., 2013, 49, 3125-3127.

8 Z. Zhang, D. Zeng, H. Ma, G. Feng, J. Hu, L. He, C. Li and C. Fan, Small, 2010, 6, 1854-1858.

9 M. Mokry, H. Feitsma, I. J. Nijman, E. de Bruijn, P. J. van der Zaag, V. Guryev and E. Cuppen, Nucleic Acids Res., 2010, 38, e116.

10 J. Martinez-Serra, J. Robles, A. Nicolas, A. Gutierrez, T. Ros, J. C. Amat, R. Alemany, O. Vogler, A. Abello, A. Noguera and J. Besalduch, J. Blood Med., 2014, 5, 99-106.

11 A. Psifidi, C. Dovas and G. Banos, PLoS One, 2011, 6, e14560.

12 P. A. Norambuena, J. A. Copeland, P. Krenkova, A. Stambergova and M. Macek Jr., Clin. Biochem., 2009, 42, 1308-1316.

13 M. Kriegsmann, N. Arens, V. Endris, W. Weichert and J. Kriegsmann, Diagn. Pathol., 2015, 10, 132.

14 S. Suthandiram, G. G. Gan, S. M. Zain, B. S. Haerian, P. C. Bee, L. H. Lian, K. M. Chang, T. C. Ong and Z. Mohamed, J. Hum. Genet., 2014, 59, 280-287.

15 K. W. Loo, L. R. Griffiths and S. H. Gan, BMC Med. Genet., 2012, 13, 34.

16 T. Ishikawa and Y. Hayashizaki, Methods Mol. Biol., 2013, 1015, 55-69.

17 Y. Enokida, K. Shimizu, J. Atsumi, A. Lezhava, Y. Tanaka, Y. Kimura, T. Soma, T. Hanami, Y. Kawai, K. Usui, Y. Okano, S. Kakegawa, H. Ogawa, Y. Miyamae, Y. Miyagi,
H. Nakayama, T. Ishikawa, Y. Hayashizaki and I. Takeyoshi, PLoS One, 2013, 8, e60151.

18 W. J. Qin and L. Y. Yung, Nucleic Acids Res., 2007, 35, e111.

19 Y. P. Bao, M. Huber, T. F. Wei, S. S. Marla, J. J. Storhoff and U. R. Muller, Nucleic Acids Res., 2005, 33, e15.

20 E. A. Josephs and T. Ye, ACS Nano, 2013, 7, 3653-3660.

21 Z. A. Crannell, A. Castellanos-Gonzalez, A. Irani, B. Rohrman, A. C. White and R. Richards-Kortum, Anal. Chem., 2014, 86, 2565-2571.

22 N. He, S. Li and H. Liu, Methods Mol. Biol., 2009, 578, 393402.

23 S. K. Rastogi, C. M. Gibson, J. R. Branen, D. E. Aston, A. L. Branen and P. J. Hrdlicka, Chem. Commun., 2012, 48, 7714-7716.

24 P. Corstjens, M. Zuiderwijk, A. Brink, S. Li, H. Feindt, R. S. Niedbala and H. Tanke, Clin. Chem., 2001, 47, 18851893.

25 X. Mao, Y. Ma, A. Zhang, L. Zhang, L. Zeng and G. Liu, Anal. Chem., 2009, 81, 1660-1668.

26 D. P. Kalogianni, L. M. Boutsika, P. G. Kouremenou, T. K. Christopoulos and P. C. Ioannou, Anal. Bioanal. Chem., 2011, 400, 1145-1152.

27 C. Xu, B. Wang and S. Sun, J. Am. Chem. Soc., 2009, 131, 4216-4217.

28 H. Yu, M. Chen, P. M. Rice, S. X. Wang, R. L. White and S. Sun, Nano Lett., 2005, 5, 379-382.

29 Y. Cui, D. Hu, Y. Fang and J. Ma, Sci. China, Ser. B: Chem., 2001, 44, 404-410.

30 W. Hui, F. Shi, K. Yan, M. Peng, X. Cheng, Y. Luo, X. Chen, V. A. Roy, Y. Cui and Z. Wang, Nanoscale, 2012, 4, 747-751.

31 D. Yang, J. Ma, Q. Zhang, N. Li, J. Yang, P. A. Raju, M. Peng, Y. Luo, W. Hui, C. Chen and Y. Cui, Anal. Chem., 2013, 85, 6688-6695.

32 F. H. Nazki, A. S. Sameer and B. A. Ganaie, Gene, 2014, 533, 11-20.

33 P. Frosst, H. J. Blom, R. Milos, P. Goyette, C. A. Sheppard, R. G. Matthews, G. J. Boers, M. den Heijer, L. A. Kluijtmans, L. P. van den Heuvel, et al., Nat. Genet., 1995, 10, 111-113.

34 X. Zhuo, J. Song, D. Li, Y. Wu and Q. Zhou, Sci. Rep., 2015, 5, 10671.

35 C. Xuan, H. Li, J. X. Zhao, H. W. Wang, Y. Wang, C. P. Ning, Z. Liu, B. B. Zhang, G. W. He and L. M. Lun, Sci. Rep., 2014, 4, 7311.

36 J. He, X. Y. Liao, J. H. Zhu, W. Q. Xue, G. P. Shen, S. Y. Huang, W. Chen and W. H. Jia, Sci. Rep., 2014, 4, 6159.

37 M. V. Holmes, P. Newcombe, J. A. Hubacek, R. Sofat, S. L. Ricketts, J. Cooper, M. M. Breteler, L. E. Bautista, P. Sharma, J. C. Whittaker, L. Smeeth, F. G. Fowkes, A. Algra, V. Shmeleva, Z. Szolnoki, M. Roest, M. Linnebank, J. Zacho, M. A. Nalls, A. B. Singleton, L. Ferrucci, J. Hardy, B. B. Worrall, S. S. Rich, M. Matarin, P. E. Norman, L. Flicker, O. P. Almeida, F. M. van Bockxmeer, H. Shimokata, K. T. Khaw, N. J. Wareham, M. Bobak, J. A. Sterne, G. D. Smith, P. J. Talmud, C. van Duijn, S. E. Humphries, J. F. Price, S. Ebrahim, D. A. Lawlor, 
G. J. Hankey, J. F. Meschia, M. S. Sandhu, A. D. Hingorani and J. P. Casas, Lancet, 2011, 378, 584-594.

38 P. Li and C. Qin, Gene, 2014, 535, 359-364.

39 L. Yan, L. Zhao, Y. Long, P. Zou, G. Ji, A. Gu and P. Zhao, PLoS One, 2012, 7, e41689.

40 Y. Huo, J. Li, X. Qin, Y. Huang, X. Wang, R. F. Gottesman, G. Tang, B. Wang, D. Chen, M. He, J. Fu, Y. Cai, X. Shi, Y. Zhang, Y. Cui, N. Sun, X. Li, X. Cheng, J. Wang, X. Yang, T. Yang, C. Xiao, G. Zhao, Q. Dong, D. Zhu, X. Wang, J. Ge, L. Zhao, D. Hu, L. Liu, F. F. Hou and C. Investigators, JAMA, 2015, 313, 1325-1335.

41 N. J. Colson, H. L. Naug, E. Nikbakht, P. Zhang and J. McCormack, Eur. J. Nutr., 2015, 1-14.

42 H. S. Cuckle, Int. J. Med. Sci., 2005, 2, 93-99.
43 C. R. Newton, A. Graham, L. E. Heptinstall, S. J. Powell, C. Summers, N. Kalsheker, J. C. Smith and A. F. Markham, Nucleic Acids Res., 1989, 17, 2503-2516.

$44 \mathrm{~S}$. Little, in Current protocols in human genetics/editorial board, ed. J. L. Haines, et al., 2001, ch. 9, Unit 98.

45 J. Liu, S. Huang, M. Sun, S. Liu, Y. Liu, W. Wang, X. Zhang, H. Wang and W. Hua, Plant Methods, 2012, 8, 34 .

46 C. M. Micklitsch, B. Y. Oquare, C. Zhao and D. H. Appella, Anal. Chem., 2013, 85, 251-257.

47 Y. Xu, Y. Liu, Y. Wu, X. Xia, Y. Liao and Q. Li, Anal. Chem., 2014, 86, 5611-5614.

48 F. Chen, Y. Zhao, C. Fan and Y. Zhao, Anal. Chem., 2015, 87, 8718-8723. 